\title{
Research on Factors Influencing Core Competitiveness of Internet Enterprises Based on AMOS Model*
}

\author{
Lihua Xia \\ School of Economics and Management \\ Taizhou University \\ Taizhou, China 225300
}

\author{
Zeyu Yang \\ School of Information and Computing Science \\ Heilongjiang University \\ Harbin, China 150001
}

\begin{abstract}
This article comprehensively considers the operating characteristics of the Internet industry, selecting 158 Internet companies as the research object and using the structural equation model, with AMOS software as the analysis tool. By building the core competitiveness verification model of Internet enterprises and selecting 10 observational variables like total $R \& D$ expenditure, total assets and assetliability ratio to explore the differences between the impact of latent variables and observation variables on core competitiveness of Internet enterprises. This article empirically studies what effect the correlation between variables and scale competitiveness, innovation risk competitiveness and operational competitiveness would have on improving the entity's core competitiveness, and puts forward countermeasures and suggestions for improvements, which provides theoretical basis for the improvement of core competitiveness of Internet enterprises.
\end{abstract}

Keywords-structural equation model; Internet enterprises; competitiveness; influencing factors

\section{INTRODUCTION}

The strategic position of China's big data industry has been further highlighted. General Secretary Xi Jinping, in his report to the Nineteenth National Congress of the Communist Party of China, pointed out that it is necessary to build a strong network country and a digital intelligent society to promote the deep integration of the real economy with the Internet and big data. The Internet has changed the production methods and life style of human beings and promoted them to move toward a higher level of information technology. Therefore, Internet industry is becoming more and more influential in the economic structure. According to Statistical Reports on Internet Development in China issued by CNNIC, as of December 2018, the number of Chinese netizens has reached 829 million, an increase of 56.53 million compared with the number in 2017. The Internet penetration rate was $59.6 \%$, the year-to-year growth rate was $3.8 \%$, and the year-on-year growth rate was $2.6 \%$. The

*Project: This paper is a phased research achievement of Taizhou University Professor's Research Fund Project "Construction of Accounting Information Platform for Small and Medium-sized Enterprises Based on Cloud Computing in the Big Data Era" (Project No.: QD2016001). proportion of users accessing the Internet via mobile phones was up to $98.6 \%$ [1]. With the recent released license on 5G system test frequency by MIIT, and major issues like toplevel plans and designs released by the Political Bureau of the Central Committee of the CPC Central Committee for the development and utilization of China's new generation of artificial intelligence, the Internet enterprises will play a more powerful role in the economy, and the industry will play an increasingly important role in the capital market. According to Wind statistics, by the end of 2018, the total market value of Internet companies listed at home and abroad has exceeded 10 trillion RMB, with the number exceeding 150. The network effect and Matthew effect are particularly prominent in the Internet industry. Enterprises with strong competitiveness in the industry are becoming stronger and stronger, while those with weak competitiveness are more worrying. Faced with such a development trend, there has been an extremely urgent problem that whether the Internet enterprises can develop and grow in an increasingly fierce competition, and to achieve value improvement in the industry.

Briginshaw (2005) regards the core competitiveness of enterprises as enterprise options, and considers that they have certain profitability to evaluate the value of Internet enterprises; Huijuan Geng (2014) and Dong He (2016) propose that the Black-Scholes model of real options can be applied to enterprise value assessment, which could take the future development opportunities of enterprises into account and compare the assessment results with the market value on the base date, achieving the conclusion that the stock price of Internet concept is undervalued [2]; Xianghong Qin (2015) believes that management theory is the most important factor affecting the value of Internet enterprises, and combines the fuzzy evaluation method with business model to construct the valuation model of Internet enterprises and verify its validity; Murphy (2016) points out that the traditional rating method is not suitable for Internet enterprises, for the difficulty on evaluating some non-financial factors [3]. Yue Ma (2016), based on Metcalfe's law and Dunbar's digital analysis of the value of Internet enterprises with large fluctuations in profitability, concludes that when evaluating the Internet enterprises, more user value factors should be 
considered [4]. The above-mentioned evaluations of the value of Internet enterprises are mostly based on the future cash flow discount model or the real option pricing model considering the contribution of users, however, the factors such as R\&D innovation, risk competition and profit model have not been attached great importance to. These evaluations are more suitable for relatively mature Internet enterprises, but not suitable for enterprises lacking steady revenue and cash flow in the initial stage and growth stage. According to the particularity of Internet enterprises and the influencing factors of enterprise value, a new value evaluation analysis model should be constructed.

\section{RESEARCH METHOD}

\section{A. Basic Principles of the Structural Equation Model (SEM)}

Structural equation modeling (SEM) originates from path analysis and factor analysis. It is a method of establishing and testing causal model. In 1970s, Keesing (1972), Wiley (1973), and Joreskog (1973) integrated factor analysis technology into path analysis and put forward a general model which marked the emergence of structural equation model [5]. It can be used to analyze the effect of individual indicators on the whole and the correlation between individual indicators, therefore, it can act as a substitution for methods like multiple regression analysis and covariance analysis. The advantage of structural equation analysis over traditional analysis is that it can deal with multiple dependent variables at the same time, and can test whether there is any change between the relationship of each variable has changed and whether the mean difference of each factor is significant.

\section{B. Construction of Structural Equation Model}

There are two basic models in the equation model: the measurement model and the structural model. The measurement model consists of manifest variables and latent variables. It is a linear function of observation variables. The manifest indicators, also known as observation variables, refer to the variables that can be measured by a specific method to obtain specific values; and the latent variables, as opposed to explicit variables, are variables that cannot be measured or observed to obtain specific values. The latent variables need to be reflected by measured indicators. The structural model is a combination of factor analysis and path analysis. It mainly studies the relationships between explicit variables, potential variables and potential variables. In the SEM analysis model, the regression relationship of the measurement model is confirmatory factor analysis, which explores the causality between latent variables and manifest variables. The regression relationship of the structural model is equivalent to the traditional path analysis, which directly explores the causality between potential variables.

The regression equation of the measurement model is:

$\mathrm{Xn}=\lambda \mathrm{n} \zeta \mathrm{n}+\delta \mathrm{n}$

$\mathrm{Yn}=\lambda \mathrm{n} \eta \mathrm{n}+\varepsilon \mathrm{n}$
The regression equation can be expressed as a matrix equation as following:

$$
\begin{aligned}
& \mathrm{X}=\Lambda \mathrm{x} \zeta+\delta \\
& \mathrm{Y}=\Lambda \mathrm{y} \eta+\varepsilon
\end{aligned}
$$

There is no correlation between $\zeta$ and $\delta, \eta$ and $\varepsilon$, and vice versa. $\Lambda \mathrm{x}$ and $\Lambda \mathrm{y}$ are the factor loading of index variables $(\mathrm{X}, \mathrm{Y}), \delta$ and $\varepsilon$ are measurement errors of observation variables; $\zeta$ is the explicit variable, $\eta$ is the potential variable of internal derivation. Besides, the SEM measurement model assumes that there is no covariant or causal path between potential variables and measurement errors [7].

At present, the software that can deal with SEM includes AMOS, LISREL, EQS, Mplus, R. Amos (Analysis of Moment Structures) moment structure analysis. It is visual module software that combines with linear model and common analysis techniques, having similar connotation of structural analysis to covariance matrix, to be used to estimate the initial model diagram, verifies the adaptation effect, and outputs the optimal adaptation model after modifying according to the revised index.

\section{CONSTRUCTION AND EMPIRICAL TEST ANALYSIS OF} THE VALUE EVALUATION MODEL OF INTERNET ENTERPRISES

\section{A. Sample and Variable Selection}

Referring to the industry classification guidelines, this paper selected the 2018 data of six typical types of Listed Companies in the Internet industry in Shanghai and Shenzhen Stock Exchanges as samples, including 47 Internet games, 16 e-commerce, 19 interconnected finance, 23 software tools, 75 Internet of Things, 16 digital cultural media, and 158 companies dealt with by ST. The data in this paper are collected from Guotaian and RESSET series research databases. In order to better evaluate the company's value, it is necessary to preliminarily select indicators and conduct exploratory factor analysis on the data.

TABLE I. TEST OF KMO AND BARTLETT

\begin{tabular}{|c|l|l|}
\hline \multicolumn{2}{|c|}{ K-M-O Metric } & 725 \\
\hline Bartlett & Approximate chi square & 674.093 \\
\cline { 2 - 3 } $\begin{array}{c}\text { Sphericity } \\
\text { Test }\end{array}$ & df & 66 \\
\cline { 2 - 3 } & Sig. & 000 \\
\hline
\end{tabular}

The sphericity $\mathrm{P}$ value is significantly less than 0.05 , and $\mathrm{KMO}$ is greater than 0.7. (As shown in "Table I")There are significant differences between variables and unit array, which is suitable for factor analysis. Orthogonal rotation is selected to extract the cumulative square sum loading value of $78.38 \%$ according to the cumulative explanatory rate of factor variance. The three principal components can cover most of the information of the original variables. Their components are selected as exogenous latent variables and named as scale competitiveness, innovation risk competitiveness and operational competitiveness respectively. The relationship between the latent variables 
and their corresponding observed variables is shown in

"Table II".

TABLE II. DEFINITION OF VARIABLES

\begin{tabular}{|c|l|l|l|}
\hline Dimension & \multicolumn{1}{|c|}{ Variable Name } & \multicolumn{1}{|c|}{$\begin{array}{c}\text { Variable } \\
\text { Symbol }\end{array}$} & \multicolumn{1}{|c|}{ Variable Interpretation } \\
\hline Industry status & enterprise value & Val & Per share price * total number of shares \\
\hline \multirow{2}{*}{$\begin{array}{c}\text { Scale } \\
\text { Competitiveness }\end{array}$} & Operating income & Opin & Total annual operating income \\
\cline { 2 - 4 } $\begin{array}{c}\text { Innovative } \\
\text { Competitiveness }\end{array}$ & Total assets & Ta & Total assets for the whole year \\
\cline { 2 - 4 } & Asset-liability ratio & $\mathrm{Alr}$ & Total annual R\&D expenditure \\
\cline { 2 - 4 } & Current ratio & $\mathrm{Cr}$ & Total liabilities/total assets \\
\cline { 2 - 4 } & Net operating cash flow & Nocf & $\begin{array}{l}\text { Operational Cash Flow-Operational } \\
\text { Cash Flow }\end{array}$ \\
\hline \multirow{2}{*}{$\begin{array}{c}\text { Operational } \\
\text { Competitiveness }\end{array}$} & Return on net assets & Rona & Net profit/average net assets \\
\cline { 2 - 4 } & Growth rate of income & Groi & $\begin{array}{l}\text { Increase in Operating Revenue/Current } \\
\text { Operating Revenue }\end{array}$ \\
\cline { 2 - 4 } & Earnings per share & Eps & Net profit/total number of shares issued \\
\cline { 2 - 4 } & Total asset turnover & Tat & $\begin{array}{l}\text { Operating Revenue/Average } \\
\text { Assets }\end{array}$ \\
\hline
\end{tabular}

\section{B. Construction of Initial Model}

AMOS 24.0 software was used to construct a model for validation analysis and to explore the relationship between latent variables and observed variables. According to the set latent variables and corresponding observation variables, the initial model path map of Internet enterprise value analysis structural equation is constructed, as shown in "Fig. 1".
Because of the different data dimensions, in SPSS 19.0, the operation command of "analysis-description statisticsdescription" is executed, and the standardized values are saved as variables to reduce the error. The most commonly used method of SEM estimation is maximum likelihood estimation, which is used to estimate various parameters in the model. Sample data conform to the multivariable normality assumption.

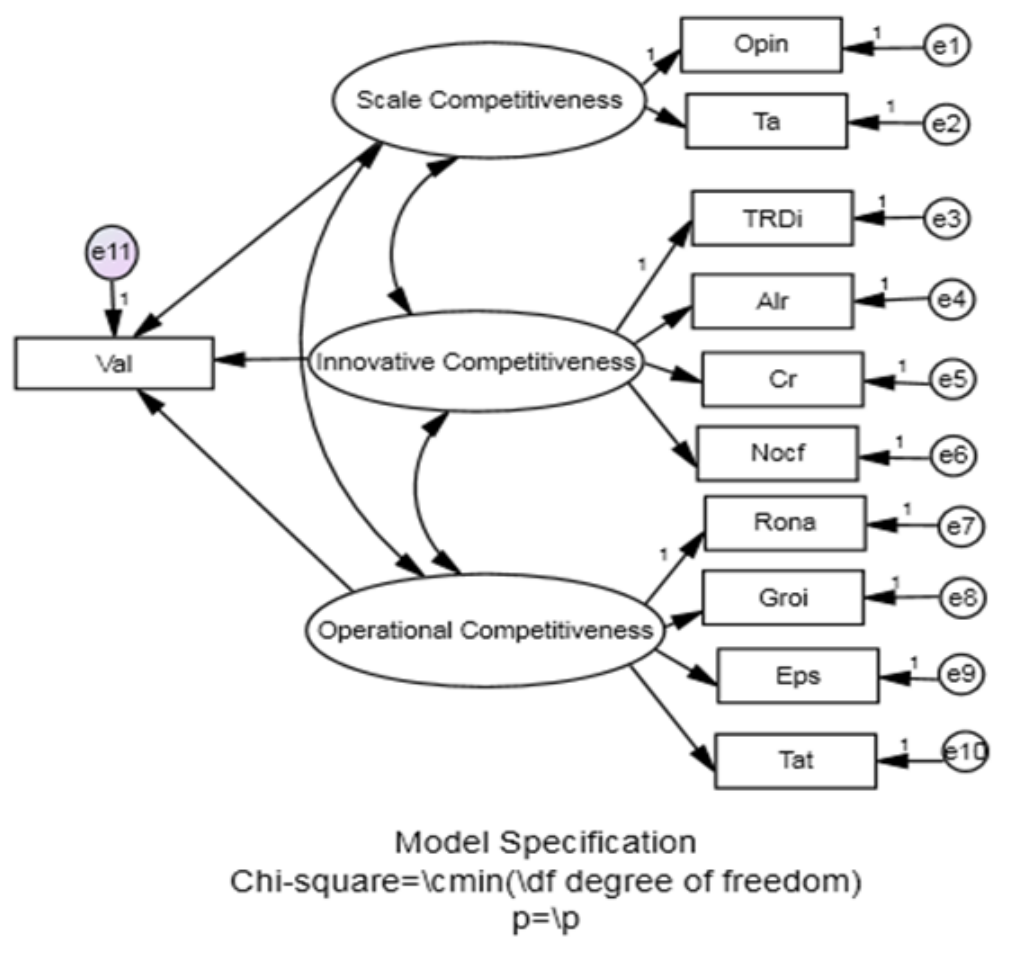

Fig. 1. Initial path map of structural equation model for internet enterprise value analysis. 
The operation calculation is checked. The standardized output parameters of the model are between 0 and 1 except the reverse index asset-liability ratio, which is in line with the actual operation. However, the answer of $X \sim 2$ to degree of freedom of commonly used absolute fitness index, $\mathrm{CMIN} / \mathrm{DF}=6.351$ (normal range is less than 3), RMSEA $=0.19$ (better fit than 0.08), GFI $=0.817, \mathrm{NFI}=0.690$ (better fit than 0.9), $\mathrm{P}=0.012$, less than 0.05 , rejecting the assumption of initial model setting, needs to be carried out according to the parameter prompts [8].

\section{Fitting and Modifying Model}

"Table III" is the initial validation result of the model. At the significant level of $\mathrm{p}=0.05$, only the path coefficients between innovation risk competitiveness and asset-liability ratio are not significant, while the path coefficients between the other latent variables, observation variables and observation variables are significant.

TABle III. Model Estimation Parameter Table Regression Weights: (Group Number 1 - Default Model)

\begin{tabular}{|c|c|c|c|c|c|c|}
\hline & & & Estimate & S.E. & C.R. & $\mathbf{P}$ \\
\hline Opin & <--- & Scale Competitiveness & 1.000 & & & \\
\hline$T a$ & $<--$ & Scale Competitiveness & 0.923 & .065 & 18.882 & $* * *$ \\
\hline Alr & $<--$ & Innovative Competitiveness & -.945 & .210 & -4.512 & $* * *$ \\
\hline Cr & $<--$ & Innovative Competitiveness & .027 & .113 & .238 & .812 \\
\hline Nocf & $<--$ & Innovative Competitiveness & .331 & .192 & 1.725 & .015 \\
\hline Rona & <--- & Operational Competitiveness & 1.000 & & & \\
\hline Groi & $<--$ & Operational Competitiveness & .209 & .083 & 2.515 & .012 \\
\hline Eps & $<--$ & Operational Competitiveness & .683 & .104 & 6.590 & $* * *$ \\
\hline Tat & $<--$ & Operational Competitiveness & .113 & .051 & 2.213 & .027 \\
\hline$T R D i$ & $<--$ & Innovative Competitiveness & 1.000 & & & \\
\hline Val & $<--$ & Scale Competitiveness & .956 & .126 & 7.613 & $* * *$ \\
\hline Val & $<--$ & Operational Competitiveness & .355 & .068 & 5.250 & $* * *$ \\
\hline Val & <--- & Innovative Competitiveness & .479 & .297 & 1.613 & .017 \\
\hline
\end{tabular}

Looking at the "Modification Indices" option in the output results, through the covariance correction index table (see "Table IV"), it can be concluded that e1 and e10 are error variables of the observation variables "business income" and "total asset turnover rate". In the initial model, there is no correlation between them. From the calculation formula, there is a covariant relationship between them, if there is a correlation between them. In this system, if the error term between the observed variables is relaxed from the strictly unrelated assumption, the answer of $\mathrm{X} \sim 2$ can be reduced by at least 87.768 , and the parameter estimation will be changed by 0.446 . The two variables are connected by double arrows.

TABLE IV. COVARIANCE CORRection IndeX TABle COVARIANCES: (Group Number 1 - Default Model)

\begin{tabular}{|c|c|c|c|c|}
\hline & & & M.I. & Par Change \\
\hline e10 & $\langle-->$ & Innovative Competitiveness & 19.514 & -.253 \\
\hline$e 8$ & $\langle--\rangle$ & $\mathrm{e} 10$ & 4.460 & .168 \\
\hline$e 7$ & $\langle->$ & e3 & 4.039 & -.093 \\
\hline$e 9$ & $\langle->$ & Scale Competitiveness & 4.094 & .093 \\
\hline$e 6$ & $\langle->$ & Operational Competitiveness & 5.101 & .180 \\
\hline$e 4$ & $\langle--\rangle$ & e10 & 17.293 & .301 \\
\hline$e 2$ & $\langle--\rangle$ & e10 & 42.578 & -.264 \\
\hline$e 2$ & $\langle--\rangle$ & e8 & 4.903 & -.088 \\
\hline$e 1$ & $\langle-->$ & Innovative Competitiveness & 5.753 & -.081 \\
\hline$e 1$ & $\langle--\rangle$ & e10 & 87.768 & .446 \\
\hline$e 1$ & $\langle--\rangle$ & e6 & 4.242 & -.097 \\
\hline
\end{tabular}

According to the M.I. index value provided by AMOS, each time a parameter is released, a new path is added to the model. After each modification, the revised index of error variables e 2 and e10, e 3 and e10, e4 and e10 is higher. Corresponding observation variables show that there is a symbiotic relationship between total assets and total assets turnover, total $\mathrm{R} \& \mathrm{D}$ expenditure and total assets turnover. There is an inevitable relationship between the asset-liability ratio and the total asset turnover ratio. It is needed to relax the error terms of these observation variables in turn, which will improve the fitting effect of the model obviously [9]. Therefore, these pairs of error variables are connected by double arrows in the structural equation path diagram. According to the output results, the overall fitting situation is sorted out, as shown in "Table V". 
TABLE V. OVERALl FitTing TABLE

\begin{tabular}{|c|l|l|l|}
\hline Fitting index & Before model updating & \multicolumn{1}{|c|}{ Modified model } & \multicolumn{1}{|c|}{$\begin{array}{c}\text { Standard or critical value of } \\
\text { fitting index }\end{array}$} \\
\hline $\boldsymbol{P}$ & 0.012 & 0.25 & $>0.05$ \\
\hline $\boldsymbol{C H I / D F}$ & 6.351 & 1.168 & $<3$ \\
\hline $\boldsymbol{R} \boldsymbol{M} \boldsymbol{E} \boldsymbol{A}$ & 0.19 & 0.034 & $\begin{array}{l}<0.08 \text { (The smaller the index value, } \\
\text { the better the fitting is.) }\end{array}$ \\
\hline $\boldsymbol{G F I}$ & 0.817 & 0.959 & $>0.9$ \\
\hline $\boldsymbol{N F I}$ & 0.690 & 0.942 & $>0.9$ \\
\hline $\boldsymbol{C F I}$ & 0.824 & 0.991 & $>0.9$ \\
\hline
\end{tabular}

From the above table, it can be concluded that after model modification, the fitting index can reach or surpass the fitting standard, reflecting that the fitting between model and data is good. The modified model can fit the sample data and meet the absolute adaptability requirements. The constructed model is in good agreement with the actual situation, and the path analysis results are reliable. The revised model path is shown in "Fig. 2".

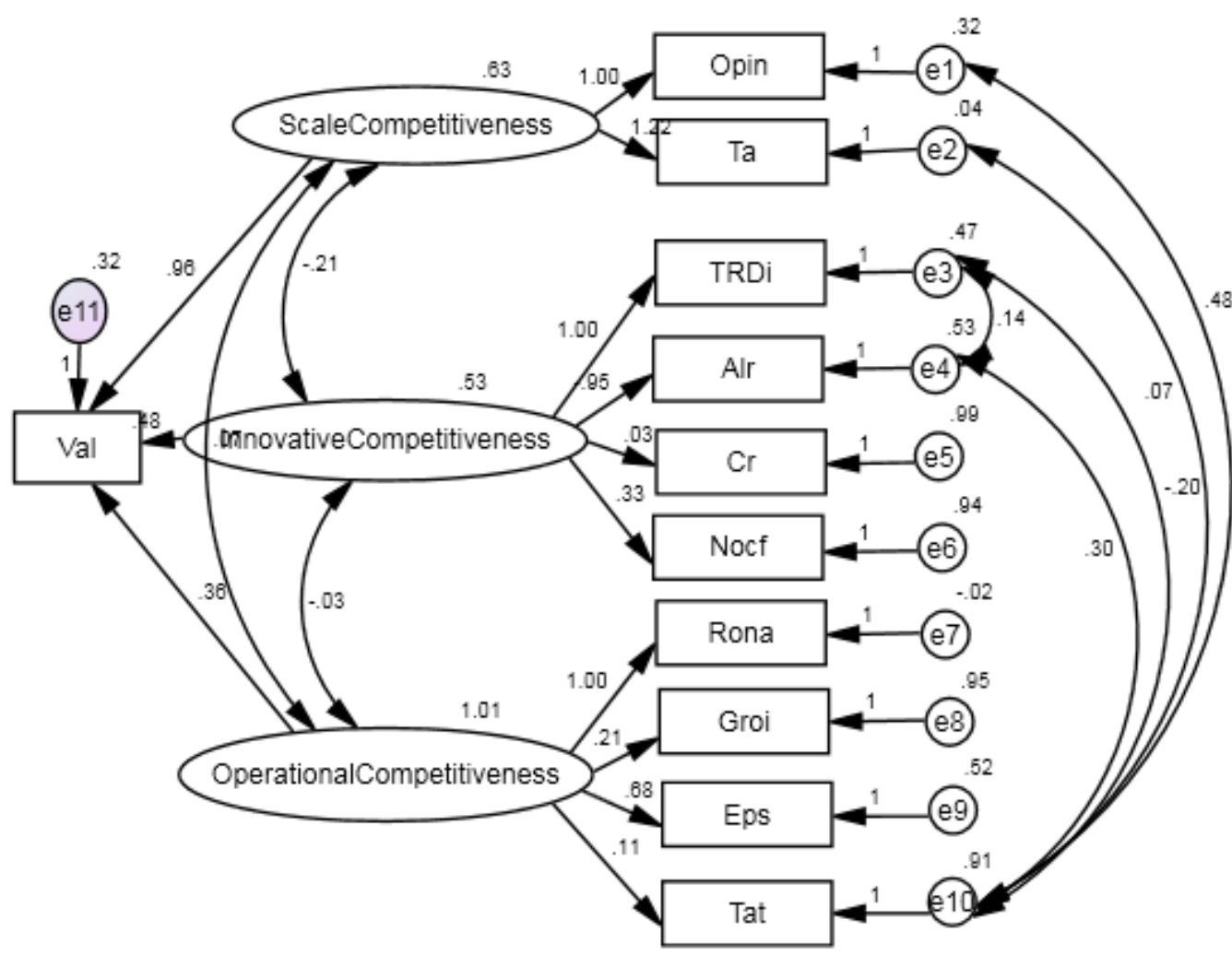

\section{Standardized estimates Chi-square $=31.532$ ( 27 degree of freedom) $p=.250$}

Fig. 2. Revised structural equation model path map for internet enterprise value analysis

There are 23 variables in the structural equation model, including 10 observational variables, 13 potential variables, 10 internal variables, 13 external variables (including 3 potential variables plus 10 error variables), and the index variables of the measurement model are observational variables. The number of unique sample moment elements is the number of sample data points, the value is $\mathrm{k}(\mathrm{k}+1) / 2=$ 55 , where $\mathrm{k}$ is the number of observed variables of CFA model. There are 28 free parameters with estimation in the model. The degree of freedom of the model is 27 , the answer of $\mathrm{X} 2$ is 31.532 , and the significance probability value is $p=0.250>0.05$. The null hypothesis is accepted to support the hypothesis that the variance covariance $\mathrm{S}$ matrix derived from the observation data is equal to the variance covariance matrix derived from the hypothesis model, that is, the hypothesis model diagram is suitable for the observation data. In the estimation of measurement model, the parameter of a certain index variable is fixed to 1 between the latent 
variable and the path coefficient of its observation variable. As for which index variable is fixed, it has no relation. Because after testing with specific data, the value-type maps of standardized estimation of measurement model are the same and the overall fitness statistics are the same [6].

\section{Research Conclusion}

Empirical research shows that the path coefficients of scale competitiveness, innovation risk competitiveness and operational competitiveness of endogenous latent variables to the core value of Internet enterprises are $0.76,0.35$ and 0.36 , respectively. There is a causal relationship between the three factors and the core value of enterprises and they are positive. Scale competitiveness is the most important factor affecting the core competitiveness at the current stage. In contrast, innovation risk competitiveness is the most important factor. And the influence of operational competitiveness is weak; the company can give priority to scale, in order to enhance its value and core competitiveness faster.

Comprehensive evaluation of the representativeness and interrelationship of the observed variables shows that the total assets and revenue of the observed variables representing scale competitiveness have the highest overall standardization effect on core value, and the total assets have a strong explanation for scale competitiveness ( $\lambda=$ 0.98).Total R\&D expenditure and asset-liability ratio have strong explanations for innovation risk ability ( $\lambda$ is greater than 0.69), which coincides with the current situation that Internet enterprises attach importance to $R \& D$ expenditure to enhance core value. The total $R \& D$ expenditure of leading enterprises in the industry and the proportion of $R \& D$ expenditure to business income show an upward trend year by year; the impact of liquidity ratio and net operating cash flow on innovation risk ability The main reason is that the asset characteristics of the Internet industry are light assets and high liquidity ratio. Because of the favor of investors, the cash flow of enterprises in the industry is generally higher than that of other industries, which belongs to the industry commonness and cannot constitute a specific factor to explain the value of enterprises.

Return on net assets has the strongest explanatory power to operational competitiveness, and the corresponding explanatory power is close to 1 . The explanatory power of earnings per share to operational competitiveness is slightly weaker than that of return on net assets ( $\lambda$ is close to 0.7 ); the explanatory power of growth rate of operating income and turnover rate of total assets to operational competitiveness is weak, because many Internet enterprises adopt "burning money" in the initial stage. " The growth of business income, especially in the initial stage, has some difficulties, which cannot be well used to explain the improvement of the core competitiveness of enterprises; the turnover rate of total assets is reflected by the ratio between business income and average total assets, while the turnover rate of business income and total assets has been a good explanation for the value of enterprises in terms of scale competitiveness instead of total assets turnover rate. If the company data is incomplete or lagged, the observation variables with high explanatory degree can be selected to measure.

Different from traditional industries and general understanding, the impact of operating capacity on the core competitiveness of Listed Companies in China's Internet industry is not the most significant. The correlation between the size of Listed Companies in the Internet industry and innovation risk capability, innovation and operation capability, scale and operation capability is not significant. It shows that there is a lag between the expansion of the company's scale and the profit and capital turnover movement. At the same time, the rapid development of the Internet industry, the long profit cycle and the high cash flow characteristics lead to the relationship between profit and risk is not as close as in the traditional industry.

\section{COUNTERMEASURE AND ENLIGHTENMENT}

\section{A. Enhancing Scale Competitiveness}

Internet industry follows the law of increasing scale value. The externality of network will have a positive impact on the value of enterprises. The increasing effect of scale income of Internet enterprises is more obvious than that of other industries, because the main products of Internet industry generally have the characteristics of extensive replication without cost. With the expansion of scale, the average cost is decreasing, the income is increasing, and the price of enterprises is increasing. Value will increase, and at the same time it will promote more users to enter, forming a cycle of increasing law.

At present, the competition in the Internet industry has entered a period of how to take measures to attract consumers 'attention from the previous period of fighting for demographic dividends. Whether it is the Internet giant who has been working for many years or the new entrants who are constantly engaged in the hot flashes, they are well versed in this way. With the continuous development of the Internet, it has brought infiltration among various industries, cross-links of industrial relations and the improvement of user stickiness. More and more enterprises are aware of the great value of common user groups among different kinds of websites. This index will promote the integration of Internet enterprises 'business forms and provide a new reference dimension for enterprises to analyze user behavior more accurately. This is in line with the conclusion drawn from the empirical study. Scale competitiveness is an important factor to enhance the value of the Internet industry.

\section{B. Creating a Characteristic Profit Model}

Although most Internet companies adopt the "burning money" operation mode when they start up, they still need to consider the distinctive profit points when they start up companies, so as to gain profits as soon as possible and achieve higher value. Through the combination of long-term strategic planning and short-term business plan to adapt to the external environment, enterprises and users will win-win. The value of users lies in creating profits for enterprises while consuming, while enterprises strive to make users 
loyal to and dependent on their products or services. Therefore, they need products with characteristics and service quality should be higher. For example, Oriental Pearl based on smart operation driven "entertainment + " strategy, complying with the general trend of upgrading and transformation of consumption, meeting users' diversified consumption needs of entertainment, building the industry's leading OPG cloud, forming the core technical support of business development through cloud technology, big data and artificial intelligence, so as to achieve technological backstage access, data access and access to users and services. To achieve cross-industry, online and offline wisdom links, multi-terminal consumer experience and multi-dimensional user flow value realization, the core competitiveness of Internet media has been improved.

\section{Continuously Improving the Level of Innovation Technology}

The industry is facing the challenges of diverse, complex and rapid changes in technology and services. New applications, new channels and new business models brought by new technologies such as artificial intelligence, VR, AR and block chain bring new opportunities and challenges to the development of the Internet industry. In order to adapt to these changes, enterprises should conduct in-depth research and experiments on new technologies and new businesses, and continuously improve their technological innovation capabilities. Through external expansion and internal collaboration, it is needed to further optimize and improve the big data industry ecosphere, promote the deep integration of big data, cloud services and artificial intelligence, and focus on exploring a reasonable and efficient mechanism for industrial co-development.

\section{CONCLUSION}

The rapid development of the Internet industry drives the evaluation of enterprise value and core competitiveness to become an important research topic. At present, more and more traditional valuation methods are based on. More effective evaluation models for Internet enterprise value need to be explored. In the future research process, customers' distance from enterprise nodes, market share, user value, and product quantity and so on should be more concerned. Note, this will be an indispensable part of improving the core competitiveness of Internet enterprises.

\section{REFERENCES}

[1] CNNIC. 43rd China Internet Development Statistics Report, Guangming Daily, 2019, 3.

[2] Wang Linling. Research of the Internet Enterprise Value Assessment [D]. Harbin: Harbin Institute of Technology, 2018.

[3] Wang Yonggang. Research on the internet enterprise value evaluation [J]. Economic Research Guide, 2015, 31(20): 12-35.

[4] Benter P. M, Chou C.p. Practical Issues in Structural Modeling [J]. Sociological Methods and research, 1987, (16): 78-117.

[5] Yi Danhui. Structural Equation Model Method and Application [M]. Beijing: Renmin University Press, 2008.7.

[6] Wu Minglong. Structural Equation Model-Operation and Application of AMOS [M]. Chongqing University Press, 2009.7.
[7] Hou Jietai, Wen Zhonglin, Marsh Herbert. Structural Equation Model Test: Fitting Index and Chi-square Criterion [J]. Journal of Psychology, 2004.02: 186-194.

[8] Song Dandan. Research on the Influential Factors of Chinese Security Companies' Core Competitiveness Based on SEM. Universities directly under the Ministry of Education. 2015. 05.

[9] Meng Ge. Research on Earnings Quality of Chinese Manufacturing Corporation Based on Structural Equation Model. Master's Degree Thesis of Northeast University of Finance and Economics, 2015.10. 